\title{
A PESQUISA COMO POSSIBILIDADE DE RESSIGNIFICAC̣ÃO DAS PRÁTICAS DE ENSINO NA ESCOLA NO/DO CAMPO
}

\author{
Rosenilde Nogueira Paniago* \\ Simone Albuquerque da Rocha** \\ Josenilde Nogueira Paniago***
}

RESUMO: Este trabalho trata de investigação realizada em uma escola do campo, em Mato Grosso, com professores e alunos da Educação Básica, e objetivou analisar a possibilidade da ressignificação da prática de ensino de Ciências e de Matemática, utilizando a pesquisa no coletivo escolar como ferramenta pedagógica. A investigação realizada a partir da abordagem qualitativa, tendo a observação participante, o diário de campo e entrevistas como instrumentos, apontou a formação do professor para a pesquisa como possibilidade significativa para a problematização, intervenção, transformação das questões socioambientais, contradições sociais da vida do campo e ressignificação das práticas de ensino.

Palavras-chave: Ensino e aprendizagem de Ciências Naturais e Matemática. Ensino Fundamental. Pesquisa. Educação no/do Campo.

\section{RESEARCH AS A POSSIBILITY OF REINTERPRETATION OF TEACHING IN RURAL SCHOOLS}

ABSTRACT: This paper is a survey conducted in a rural school with teachers and students of Grammar School in the state of Mato Grosso, Brazil. This study aimed to analyze the possibility of reframing the practice of teaching Science and Mathematics by using research within the school community as a pedagogical tool. The research uses a qualitative approach along with participative observation, a field diary and interviews, determining that a teacher with training of research is a significant opportunity for fostering inquiry, intervention, transformation of environmental issues and the social contradictions of rural life as well as the reframing of teaching practices.

Keywords: Teaching and Learning of Science and Mathematics. Basic Education Research. Rural Education.
*Doutoranda do Instituto de Educação, Universidade do Minho, Portugal. Possui Mestrado em Educação através do Programa de Educação da Universidade Federal de Mato Grosso. Graduação em Licenciatura Plena em Matemática pela Universidade Federal de Mato Grosso (1999). Professora do Instituto Federal Goiano, Campus de Rio Verde, Goiás, onde atua na área de Ensino de Ciências:

Formação de Professores e como coordenadora de gestão institucional do Programa

Institucional de Bolsas de Iniciação a Docência ( PIBID). Faz parte do grupo de pesquisa Educação

do Instituto Federal Goiano e do grupo Investigação da Universidade Federal de Mato Grosso, com pesquisas nas áreas de Educacão do Campo, Educação a Distância Formação de Professores e Ensino de Ciências. Email: rosenilde_nogueira@yahoo.com.br

* Doutora em Educacão pela Universidade Estadual Pauliste Júlio de Mesquita Filho (2001) e Pós-Doutorado pela PUC-SP

(2011). Professora associada na Universidade Federal de Mato Grosso. Líder do grupo de Pesquisa investigcão e Vice-coordenadora do PPGEdu/UFMT.

Email: sa.rocha@terra.com.br

** * Graduada em Ciências Biológicas pela Universidade do Estado de Mato Grosso. UNEMAT (1996), Pós Graduada em Metodologia do Ensino de Ciências e Metodologia do Ensino a Distância (UFMT). Professora da rede de Educacão Básica de Mato Grosso, desde 1989, em que atuou como Professora, como Gestora e Coordenadora. Desempenhou 0 papel de Orientadora Acadêmica no

Curso de Pedagogia em EAD pela

Universidade do Estado de Mato Grosso (2000-2001).

Email: josypaniag02012@hotmail.com 


\section{CONSIDERAÇÕES INICIAIS}

Ao propormos uma investigação sobre o uso da pesquisa no cotidiano da educação básica, já antevíamos o desafio dessa empreitada, na medida em que vários teóricos da literatura brasileira e estrangeira reforçam ser fundamental essa prática. Porém, a pesquisa do professor da educação básica ainda não conta com critérios próprios, e não está claro qual o tipo de análise ideal para resolver os problemas do cotidiano escolar. Nesse sentido, é oportuno destacarmos que, no presente estudo, não discutiremos as exigências que envolvem tal prática, mas, embora não as esquecendo, queremos deixar clara nossa intenção em analisar a possibilidade da ressignificação da prática de ensino de Ciências Naturais e de Matemática, utilizando a pesquisa no coletivo escolar como ferramenta pedagógica. A investigação foi realizada em uma escola do campo que atende dois projetos de assentamento, no interior de Mato Grosso.

A inserção da pesquisa na formação e no trabalho docente é um tema que está incluído, de forma latente, em programas de formação. Conforme as diretrizes curriculares para a formação inicial, criadas pelo MEC, por meio do Conselho Nacional da Educação (2000, p. 47):

A pesquisa constitui um instrumento de ensino e um conteúdo de aprendizagem na formação, especialmente importante para a análise dos contextos em que se inserem as situações cotidianas da escola, para construção de saberes que ela demanda e para a compreensão da própria implicação na tarefa de educar [...].

Observa-se que a lei estabelece a pesquisa como ferramenta de ensino indispensável à prática docente e como sendo necessária à formação do professor, no sentido de possibilitar-lhe refletir sobre situações práticas do seu cotidiano e nelas intervir. Nesse sentido, o GEPprof (Grupo de Estudos sobre a Profissão Docente da Pontifícia Universidade Católica do Rio de Janeiro) tem contribuído, de forma significativa, com essa discussão, ao provocar uma reflexão sobre a importância da pesquisa do professor da educação básica como alternativa para a construção de conhecimentos, sobre o que conta ou não como pesquisa e a necessidade de se pensar, de acordo com Ludke (2009, p.106) em “[...] formas e modalidades que se aproximem mais das características próprias do professor, sem descuidar, entretanto, das exigências dirigidas a toda pesquisa”.

A pesquisa na prática docente pode se tornar um instrumento de mediação entre os conteúdos conceituais e os saberes dos alunos. Entretanto, apesar de essa discussão estar se intensificando, mudanças pouco significativas foram feitas até então. Ainda prevalecem, no ambiente escolar, práticas de ensino sem conexão com o ambiente natural do aluno e entre as várias áreas de conhecimento, por conseguinte, a falta de contextualização dos conteúdos com a realidade vivenciada pelos estudantes e o trabalho com os saberes das várias ciências, de forma fragmentada, não possibilitam uma aprendizagem significativa, a análise, a compreensão dos problemas da realidade e a intervenção com intenções transformadoras. 
A presente investigação resulta, portanto, de nossa preocupação com tais questões, em função do envolvimento com a educação do campo e com a formação de professores. Como educadores, não podemos ficar alheios às questões socioculturais, ambientais e econômicas do aluno do campo, pois não se concebe mais desenvolver um ensino obsoleto, desconectado dessa realidade, conforme aponta Molina (2006, p. 12):

A desvalorização dos conhecimentos práticos/teóricos que trazem os sujeitos do campo, construídos a partir de experiências, relações sociais, de tradições históricas e principalmente, de visões de mundo, tem sido ação recorrente das escolas e das várias instituições que atuam nestes territórios.

O contexto ambiental das escolas do campo possui um laboratório vivo, com várias possibilidades a serem trabalhadas no processo educativo escolar, o que implica ao professor problematizar as questões vividas pelo aluno nesse espaço e valorizar os seus saberes. Como pesquisadora, professora e gestora, nos estudos de formação continuada e na relação estabelecida com a comunidade escolar, o objetivo era deflagrar um processo de reflexão e problematização, junto ao grupo, acerca de questões que contemplavam, desde a inserção como professora naquele contexto social, cultural e ambiental, até as práticas sociais e ambientais envolvidas, salientando, para isso, a importância da gestão democrática e do planejamento participativo.

Sendo o objeto da presente investigação o ensino e a aprendizagem de Ciências Naturais e de Matemática, priorizamos a problematização das questões socioambientais, considerando que o campo tem um alto passivo ambiental provocado pela produção da agricultura. Nesse sentido, a questão ambiental é uma preocupação cada vez mais presente na sociedade, fato este que implica na necessidade de um ensino voltado para a temática que venha a contribuir para a formação de sujeitos críticos, que busquem a conservação da vida do planeta, melhores condições sociais para a existência humana, e que possam participar da tomada de decisões acerca das questões científicas e tecnológicas.

Não obstante, é preciso refletir, a partir do ideário de Chalmers (1999), sobre o fato de que os avanços tecnológicos, em diversas áreas, e os benefícios gerados, a partir da utilização dos resultados de pesquisas científicas, passam a ideia de que tudo o que é "cientificamente comprovado" merece atenção e pode trazer frutos para a população. Por outro lado, o que traz conforto e que poderia ser visto como melhor qualidade de vida, tem trazido sérias consequências para a população e para o planeta. Não é possível, portanto, desenvolver um ensino e uma aprendizagem sem relação com essas questões, do modo como geralmente acontece na escola, em que, conforme Trivelato (2000, p.48), "[...] não há uma preocupação em promover atividades em que os alunos se deparem com a solicitação de tomar posições e de construir juízos de valor”). É preciso avançar da condição de um ensino amorfo, distanciado da realidade dos alunos do campo, da formação de pessoas acríticas, passivas, para um ensino vivo, contextualizado, com 
a intencionalidade clara de formar cidadãos de forma que sejam produtores e não apenas reprodutores de conhecimento.

Assim, o ensino na escola do campo pode contar com a pesquisa a fim de que os professores suscitem nos alunos uma reflexão sobre a forma como a população recebe informações acerca das ciências e de suas tecnologias e o conhecimento que possuem sobre a forma como sua vida pode ser afetada pelos avanços decorrentes do conhecimento científico. Nessa perspectiva, concordamos com Fourez (1994) ao vislumbrarmos um ensino que incite o desenvolvimento do espírito crítico e investigativo do aluno, para que ele seja capaz de refletir criticamente acerca dos impactos dos avanços científicos e tecnológicos.

Diante do exposto, a investigação foi direcionada pelas seguintes questões: "Como trabalhar o ensino das Ciências Naturais e da Matemática na escola do campo utilizando a pesquisa como ferramenta pedagógica de ensino?", "Como articular os conhecimentos teóricos das Ciências Naturais e da Matemática à vida e aos saberes dos jovens do campo?”, "Como engajar os professores em um processo coletivo de pesquisa, no cotidiano escolar, de modo a suscitar nos alunos o espírito de investigação e iniciação à pesquisa?”.

\section{METODOLOGIA}

Para responder às questões do estudo, buscamos os fundamentos na abordagem qualitativa, pois nesse tipo de tratamento, de acordo com Bogdan e Biklen (1994), os pesquisadores estão interessados no modo como diferentes pessoas dão sentidos às suas vidas, naquilo que experimentam, como interpretam as suas experiências e na maneira como estruturam o mundo social em que vivem.

Utilizamos, como instrumentos de coleta de dados na investigação, a observação participante, a entrevista não estruturada, o diário de campo e fotografias. André (2001, p. 54) atribui esse crescimento diversificado de instrumentos de análise ao estudo qualitativo, afirmando que "nesse tipo de abordagem o observador não pretende comprovar teorias nem fazer generalizações estatísticas. O que busca, sim, é compreender e descrever a situação, revelar seus múltiplos significados". A observação participante se deu durante os contatos com os professores, nas observações de suas práticas, sempre permeada do diálogo, buscando explicações sobre o que pensavam atingir ao planejar determinada atividade, como definiam os caminhos e os procedimentos a serem seguidos na atividade proposta, entre outras questões, sempre no sentido de trazer maior elucidação ao investigador sobre as práticas observadas, provocando, ao mesmo tempo, reflexões no professor sobre sua proposta de intervenção.

As entrevistas foram realizadas com quatro professores, consistindo, em um primeiro momento, de um diálogo coletivo após as formações continuadas e, após, foram realizadas individualmente duas entrevistas com cada professor, uma em 2008 e outra em 2009. Os professores foram selecionados a partir dos seguintes 
critérios: interesse em participar; interesse em realizar pesquisa na prática de ensino e atuar com o ensino de Ciências Naturais e de Matemática. Objetivando preservar as suas identidades, os participantes serão identificados por pseudônimos, sendo os professores P1, P2, P3, P4. As professoras P1 e P2 são formadas em Pedagogia e ambas possuem mais de 15 anos de experiência de magistério; atuavam, na época da pesquisa, com os $3^{\circ}$ e $4^{\circ}$ anos do Ensino Fundamental. A professora P3 possui 3 anos de magistério, era licencianda em curso de Ciências e Matemática, na modalidade EAD, oferecido pela Universidade Federal de Mato Grosso, e atuava com o ensino de Ciências no $9^{\circ}$ ano do Ensino Fundamental; o professor P4, com 5 anos de magistério, atuava, de forma leiga, com Ciências e Geografia, do $6^{\circ}$ ao $8^{\circ}$ ano do Ensino Fundamental.

O diário de campo foi significativo durante o trabalho, pois nesse instrumento foram registrados todos os momentos do estudo, descrevendo os episódios e diálogos acontecidos entre investigadores e professores. Para além disso, em toda a trajetória da investigação os professores foram estimulados a refletir sobre as ações realizadas e a registrar tais processos nos diários de campo. Por conseguinte, os professores incentivaram os alunos a também fazerem uso de um caderno para registro das atividades, de modo que, por indicação dos professores, e com autorização, as impressões de três alunos, representadas nos diários de campo, foram utilizadas na análise dos dados. Os alunos, que cursavam o $9^{\circ}$ ano do Ensino Fundamental, foram nomeados A1, A2 e A3.

\section{A PESQUISA COMO ARTICULADORA DO PROCESSO ENSINO E APRENDIZAGEM DAS CIÊNCIAS DA NATUREZA E DA MATEMÁTICA NO CAMPO: AÇÃO E REFLEXÃO}

A defesa da pesquisa na formação e na prática docente tem sido alvo de intenso debate no qual vários pontos se convergem, contudo, há, ainda, muitas divergências sobre quais atividades são passíveis de serem realizadas pelos professores no cotidiano da escola, e diferentes termos são usados para identificar essa prática, conforme Pereira (2002, p.12): “[...] pesquisa-ação, investigação na ação, pesquisa colaborativa e práxis emancipatória” [...]. O que se observa é que, apesar de usarem denominações diferentes, as propostas comungam a ideia da utilização da pesquisa como ferramenta didática para abordar as temáticas curriculares.

Nessa discussão, apesar das várias convergências, há um embate teórico sobre as reais possibilidades de o professor fazer pesquisa na prática docente. André (2006, p.51) alerta-nos em relação à utilização do termo professor pesquisador/reflexivo, questionando:

[...] deve-se usar a expressão professor pesquisador/reflexivo? De que professor e de que pesquisa se está tratando, quando se fala em professor pesquisador? Que condições tem o professor que atua nas escolas, para fazer pesquisas? Que pesquisas vêm sendo produzidas pelos professores nas escolas? 
Fica evidente que a preocupação da autora é que o termo seja banalizado, utilizado para situações que não contemplem a proposta do professor pesquisador. Assim, os que defendem o uso da pesquisa na formação e no cotidiano escolar, embora enfatizem pontos diferentes, comungam com a ideia da pesquisa como estratégia de articulação entre a teoria e a prática docente. Valorizam, de acordo com Paniago e Rocha (2012, p.119):

\begin{abstract}
[...] um professor que não seja mero expectador em sala de aula e na comunidade educativa, mas que realize reflexão sobre suas ações e se torne um ator, procurando caminhos para transformar a sua realidade; caminhos esses que devem se dar no coletivo, pois as reflexões realizadas no grupo da comunidade educativa fortalecem a equipe e, por conseguinte, reflete de forma significativa na aprendizagem do aluno.
\end{abstract}

Diante do exposto, a investigação se consubstanciou no ideário que defende a pesquisa do professor em uma perspectiva crítica e política, conforme Kincheloe (1993), Pereira (2002) e Pedro Demo (1998), este último ao afirmar que (1998, p.2): “[...] educar pela pesquisa tem como condição primeira que o profissional da educação seja pesquisador, ou seja, maneje a pesquisa como princípio científico e educativo e a tenha como atitude cotidiana".

Tendo como princípio a certeza de que o trabalho coletivo teria mais significado, conforme aponta Kincheloe (1993), a partir de uma preparação teórica e metodológica de posse da qual o professor pode engajar-se coletivamente com alunos, professores e comunidade educativa, em investigações sobre problemas ligados ao cotidiano escolar para transformá-los, procuramos envolver, em todas as etapas do estudo, professores, alunos, comunidade, gestão municipal de educação, bem como outros especialistas do Instituto Socioambiental (ISA). ${ }^{1}$

A investigação ocorreu no final de 2007 e durante os anos de 2008 e 2009, quando assumimos a função de gestora e professora da escola, lócus da pesquisa. Foi realizada por meio de encontros coletivos, em um total de 80 horas, durante dois anos, tendo o espaço de formação continuada semanal como o principal momento de reunião do grupo, todavia, outras reuniões foram realizadas em grupos menores. Os momentos formativos constituíram-se em espaços destinados ao estudo e análise de textos vinculados à temática do professor pesquisador, educação científica, tipos de pesquisa qualitativa, tais como a pesquisa etnográfica, o estudo de caso, a pesquisa participante, a pesquisa-ação, a agroecologia e a educação do campo. Os referenciais teóricos foram sendo integrados aos estudos pelas possibilidades de diferentes abordagens a um tema comum, ou seja, a articulação da teoria e da prática na formação e na produção do conhecimento sobre a prática docente, a educação científica e a valorização e reconhecimento da vida no campo, no ambiente escolar.

Iniciamos a investigação dialogando, primeiramente, com os professores, nos momentos de formação continuada, questionando-os sobre a prática pedagógica, no sentido de investigar a relação entre as atividades e os conteúdos ministrados, se eles tinham algum vínculo com a vivência dos alunos, no ambiente 
do campo, em que documentos eles se baseavam para elaborar o planejamento, se conheciam as diretrizes operacionais para a educação do campo, dentre outras indagações. Os professores, de modo geral, mesmo reconhecendo a importância do trabalho, a partir da vivência dos alunos, afirmaram seguirem o livro didático, conforme depoimentos: Eu trabalho sempre o livro. Mas vejo que nem sempre ele trazo que o aluno vive aqui. O de ciências mesmo traz, por exemplo, coisas, como solo, biomas que não são daqui, mas é o que geralmente nós seguimos [...](P1, entrevista, 03/2008); em seguida, outro professor assim se manifesta: É importante quando trabalhamos com coisas daqui, da realidade deles, mas nem sempre dá para fazer isto, pois a secretaria exige que trabalhemos tudo o que está determinado no currículo, e no livro fica fácil (P2, entrevista, 03/2008).

Fica evidente que eles reconhecem que os livros não retratam as questões do campo, do ambiente, da vida dos alunos, todavia, percebemos que se tratava do principal recurso pedagógico utilizado pelos professores, na medida em que os conteúdos trabalhados eram centrados no livro didático. Nessa perspectiva, as práticas de ensino, o planejamento, a sequência didática, enfim, o processo ensino e aprendizagem, são conduzidos pelo livro didático. Para além disso, os professores possuíam receio de desenvolver outras práticas de ensino que não se configuravam nas propostas instruídas pelo sistema municipal de ensino, fato constatado em suas falas por meio das entrevistas e, conforme nossas observações, "apesar da preocupação dos professores em trabalhar com questões do contexto do aluno, é visível o receio em não seguir as normas da gestão municipal" (Diário de Campo, 10/02/2008).

Sabemos que a política escolar traduz os interesses das forças que controlam o estado, e esses interesses podem divergir das práticas sociais vividas pelo aluno, entretanto, são tarefas do professor a escolha e a definição de um planejamento de ensino que, além de respeitar os programas oficiais, contemple as práticas que ocorrem fora do espaço escolar.

A respeito das Diretrizes Operacionais ${ }^{2}$, os professores se manifestaram, afirmando: A gente sabe por leituras que temos que trabalhar com o meio do aluno, mas estou aqui há mais de 15 anos e nunca estudamos nada sobre esta lei (P3, entrevista, 03/2008). Já outro professor comunica: Eu não tenho formação, mas sou daqui e quando era aluno gostava que os professores trabalhassem assuntos daqui, mas agora que estou ouvindo falar dessa lei (P4, entrevista, 3/2008).

As falas dos professores demonstram desconhecimento da legislação e revelam que na escola não se efetiva uma educação do campo, com uma proposta pedagógica própria, que atenda as particularidades do cotidiano do aluno. Tal fato contradiz as Diretrizes Operacionais para a Educação Básica, nas escolas, ao afirmarem a necessidade de o projeto pedagógico da Escola do Campo ser vinculado aos saberes próprios dos estudantes e ao seu meio, conforme explicita o Art. $5^{\circ}$ :

As propostas pedagógicas das escolas do campo, respeitadas as diferenças e o direito à igualdade e cumprindo imediata e plenamente o estabelecido nos artigos 23,26 e 28 da Lei $\mathrm{n}^{\circ}$ 9.394, de 1996, contemplarão a diversidade do campo em todos os seus aspectos: sociais, culturais políticos, econômicos, de gênero, geração e etnia (Art. $5^{\circ}$, da Resolução CNE/CEB No 1, 2002, p.38). 
Deste modo, em nossas intervenções procurávamos trabalhar os princípios da Educação no/do campo e deflagrar, problematizar as questões que incomodavam os professores, tais como: "Como realizar um trabalho com projetos considerando a fragmentação do ensino das áreas de conhecimento, a inflexibilidade do horário, a cobrança dos dirigentes por melhores índices nas avaliações nacionais (Prova Brasil, IDEB)?", "Como associar os conteúdos básicos indicados pelas Orientações Curriculares Nacionais e os temas gerados no ambiente do aluno?", "Há possibilidade de cumprir com os conteúdos escolares oficiais previstos e o trabalho com questões da vida do aluno, por meio da pesquisa como estratégia didática?’.

Após a investigação da percepção dos professores acerca da correlação entre os conteúdos conceituais e a vivência dos alunos do campo, sobre a prática de pesquisa e da manifestação do desejo deles de participarem da investigação, suscitamos uma reflexão junto ao grupo para a definição de uma questão-problema que nortearia o trabalho coletivo, e que poderia desenvolver-se na perspectiva de Freire sobre o tema gerador. Para Freire (2005,2006), o tema gerador constitui-se como uma estratégia político-pedagógica que considera a experiência de vida dos alunos, em uma perspectiva de valorização da cultura popular, das relações dialéticas que se estabelecem entre o homem e o mundo social, comprometida com a constituição dos sujeitos. A organização do ensino sob a forma de temas geradores possibilita melhor relacionamento entre as áreas de conhecimento. $\mathrm{O}$ tema gerador dá sustentação ao estudo dos conhecimentos das diferentes disciplinas, permitindo uma interlocução sobre uma mesma temática, embora mantenha a especificidade do conteúdo.

Iniciamos, portanto, com uma decisão coletiva de investigação junto aos participantes, considerando a importância da participação de todos e da escolha de um problema relevante, principalmente, para os alunos, a fim de que o envolvimento fosse efetivo. Assim, por 30 dias os professores discutiram com os alunos, em sala de aula, instigando-os a se envolverem na escolha do tema. Foram apontadas várias temáticas, gerando, inicialmente, conflitos e divergências de ideias. Contudo, houve uma concordância geral, apontando como tema/problema, na perspectiva socioambiental, a horta escolar e a necessidade de recuperação de uma nascente que abastece a localidade.

A escolha dessa ação coletiva, na perspectiva de Freire com os temas geradores, se deu pela necessidade de nós, investigadoras, professores e alunos, vivenciarmos, de forma concreta, uma situação que tanto favorecesse uma reflexão sobre os impactos da ação humana no meio ambiente, quanto à valorização dos saberes, da vida no campo, no ambiente escolar. Assim sendo, tratava-se de um estudo de relevante conscientização e aprendizagem para a comunidade do campo, conforme aponta Arroyo (2004, p. 77):

Escola sim, mas vinculada ao mundo do trabalho, da cultura, ao mundo da produção, vinculada à luta pela terra, ao projeto popular de desenvolvimento do campo. Nós temos que recuperar os vínculos entre educação e terra, trabalho, produção, vida, cotidiano de existência; aí é que está o educativo. 
Com tal propósito, a horta foi construída no primeiro semestre de 2008, um espaço que gerou um trabalho por meio de projetos. No segundo semestre de 2008, iniciou-se o trabalho de recomposição da nascente, com sistema de agrofloresta ${ }^{3}$, que perdurou durante 2009, ano em que o trabalho foi mais significativo, pois os estudos em 2008 contribuíram para a construção de um referencial teórico acerca da pesquisa e alguns professores perceberam a importância da teoria para a realização do trabalho no cotidiano da escola, conforme afirma o professor P4: "Valeu a pena ler tanto, eu nunca achava que podia trabalhar tanta coisa a partir do que os alunos vivem" (P4, entrevista,10/2009); e também o professor P3: "Olhe, eu não gostava de ler não, mas estou vendo que tudo o que estudamos está melhorando a minha prática em sala de aula, e desperta o interesse dos alunos a partir do trabalho com a realidade deles" (P3, entrevista,10/2009). A afirmação de Ludke (2001a, p. 32) contribui com essa reflexão:

[...] uma boa formação teórica vai ajudar o professor a conhecer melhor os problemas e características da realidade que cerca a sua escola, tanto no âmbito imediato, como no mais amplo [...] o esclarecimento teórico pode lhe fornecer meios para desenvolver estratégias de luta para transformar esses aspectos, em vez de aceitá-los como imutáveis [...].

\section{O PROCESSO DE RECUPERAÇÃO DA NASCENTE DEGRADADA COMO TEMA GERADOR DO TRABALHO COM A PESQUISA NO ENSINO DE CIÊNCIAS NATURAIS E DE MATEMÁTICA NO CAMPO}

A experiência no magistério em escolas do campo, somada aos conhecimentos acadêmicos sobre a educação do campo, tem nos suscitado indignação pela falta de conexão dos conhecimentos teóricos ensinados na escola e a vida dos alunos e pela forma como os professores têm sido meros reprodutores de ideias produzidas pelos cientistas, que estão distantes da realidade das escolas. Se a ciência, os problemas científicos, se originam em situações reais, inquietantes, ligados à vida das pessoas, então, por que na escola não se discutem essas questões? Por que a ciência tem que ser reservada às mentes pensantes, aos poderosos cientistas? Por que o ensino de Ciências se desenvolve de forma desconectada da realidade do aluno, constituindo-se na transmissão de conteúdos obsoletos, fragmentados? Por que os professores que estão convivendo com as complexidades emergentes no cotidiano escolar não podem se envolver na produção de conhecimentos e na elaboração de materiais didáticos para trabalharem suas aulas? Por que tem sido constante a atuação passiva dos professores diante das normas estabelecidas pelos dirigentes da educação, seja na esfera municipal, estadual ou federal?

Tais questões nos instigam na defesa da pesquisa no cotidiano da escolar para que o professor não seja mero consumidor e transmissor de conhecimentos produzidos por pessoas alheias à sua realidade. Nessa perspectiva, faz-se necessária a educação científica voltada para a pesquisa, que pode ocorrer tanto na formação inicial quanto na continuada. Essa pode ser uma alternativa significante para que os 
professores construam conhecimentos relativos ao seu meio sociocultural, ambiental e contribuam para uma efetiva educação no/do campo, em que o no se refere a uma educação que ocorre no espaço dos alunos do campo, e o do traduz a representação de um processo educativo vinculado às questões socioculturais desse espaço.

Esse processo torna mais significativa a aprendizagem, principalmente quando ligada à docência. A pesquisa para o professor do campo se torna um rico instrumento para entender sua realidade e interagir com ela, uma vez que, conforme pontua Freire (2002, p. 32), “ [...] ensinar exige pesquisa. Não há ensino sem pesquisa e pesquisa sem ensino. Esses que fazeres se encontram um no corpo do outro. Enquanto ensino continuo buscando, reprocurando [...]".

Dessa forma, tendo a concepção de que a pesquisa é apontada por D Ambrósio (1999) como o elo entre a teoria e a prática e que ela deve ser vinculada à prática, os professores foram estimulados a trabalhar com a recuperação da área na qual se situa a nascente que fornece água para a comunidade, utilizando a pesquisa como estratégia didática, em todas as etapas: pesquisa de opinião na comunidade; pesquisa bibliográfica; pesquisa empírica, para diagnóstico das nascentes degradadas; levantamento das espécies nativas da área; coleta de sementes; época de plantio; trabalho coletivo, em formato de mutirão, para organização da área a ser recuperada; busca dos saberes populares pertinentes; tipos de plantios; luas; dentre outras.

Tendo como pressuposto que a educação é um ato dinâmico de conhecimento centrado na descoberta, na análise, na intervenção e na transformação da realidade dos que nela vivem, procuramos utilizar a pesquisa como estratégia de conhecimento e transformação da realidade vivenciada pelos professores e alunos, bem como de mediação entre os conhecimentos escolares e a vida no campo, em correlação com a resolução das Diretrizes Operacionais acerca da identidade da escola do campo: "A identidade da escola do campo é definida pela sua vinculação às questões inerentes à sua realidade, ancorando-se na temporalidade e saberes próprios dos estudantes, na memória coletiva que sinaliza frutos [...]" (Art. 2 da Resolução CNE/CEB No 1, 2002, p.37).

$\mathrm{Na}$ pesquisa empírica realizada pelos professores e alunos, sob a nossa orientação, no entorno da área de um hectare $(10.000 \mathrm{~m} 2)$ para levantamento das espécies nativas, foram identificadas mais de 50 espécies. As fotos ilustram esses momentos:

Fotos 1 e 2: Aulas de campo (identificação e coleta de sementes).
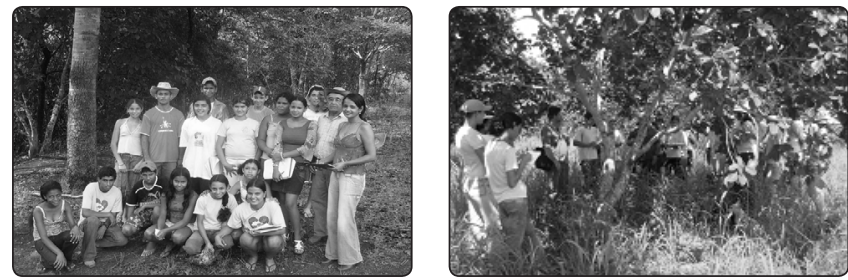

Fonte: Acervo das pesquisadoras (2008 e 2009).

Alunos do $9^{\circ}$ ano sob a orientação de pessoas da comunidade, professores participantes da pesquisa e uma das investigadoras. 
Tal levantamento sinalizou que orientássemos os professores a desenvolverem estudos, em sala de aula, sobre o processo de seleção das sementes, conservação, catalogação, quebra de dormência e cultivo no viveiro. Por meio do contato com os diversos tipos de sementes, nós (investigadoras, professores e alunos) pudemos sentir o cheiro, a textura, a cor, e percebermos que o cerrado e as matas oferecem uma beleza ímpar em frutos, flores e sementes. Essa ação nos possibilitou conhecer o cerrado em seus aspectos biológicos e ecológicos, e incitar os alunos a pesquisarem o poder nutricional dos frutos do cerrado, como foi o caso do Pequi ${ }^{4}$. Além disso, constatamos o conhecimento valioso que as pessoas da comunidade e os próprios alunos possuíam sobre os frutos desse bioma.

Concomitante ao levantamento das espécies nativas da área, foi realizada a análise físico-química e microbiológica da água da nascente. $\mathrm{Na}$ análise realizada por meio de material disponibilizado pela Empresa Brasileira de Pesquisa Agropecuária (Embrapa), foi detectada a presença de micro-organismos indicadores de poluição fecal e alterações de acidez, neutralidade e alcalinidade $(\mathrm{pH})$. A alteração da qualidade da água revelou aos alunos o impacto da ação humana nas nascentes e matas ciliares e provocou ainda mais interesse para a recomposição da área.

Após o estudo inicial, que contou com o saber de várias áreas de conhecimento, foram trabalhadas, a partir de planejamentos coletivos orientados pelas investigadoras, as características do solo, da vegetação do local, a legislação ambiental, as formas de reflorestamento, as mudanças climáticas, a germinação pela quebra de dormência, os tipos de sementes (dura, leve, moles), a função ecológica das espécies, a leitura e a produção de texto, os conceitos de medidas de comprimento, a área de figuras planas, os tipos de ângulos, estatística, porcentagem, problemas, etc. O gráfico abaixo exemplifica uma das atividades propostas:

Gráfico 1: Quantidade de indivíduos por espécie na área um hectare $\left(10.000 \mathrm{~m}^{2}\right)$ observada:

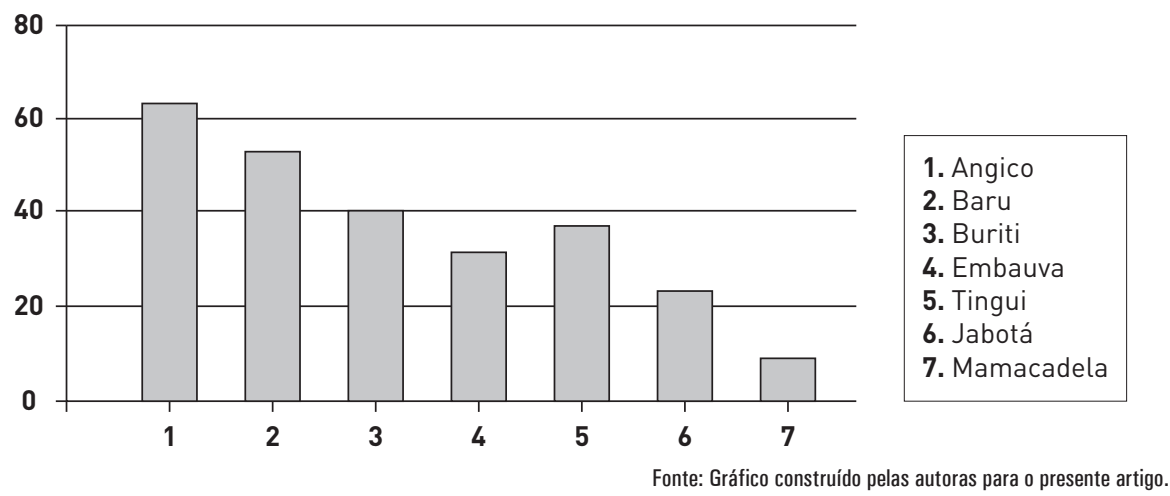

Os professores discutiram os dados com os alunos, sob a nossa orientação, considerando todos os elementos envolvidos, não apenas a quantidade de árvores que havia no local e sua representação, por meio da estatística, mas por que havia mais de uma quantidade de árvores que outras? Por que algumas haviam sido 
derrubadas? Qual a sua utilidade? Que tipo de solo favorece o desenvolvimento das diferentes espécies? Quais as consequências do desmatamento da mata ciliar? Como se conservam rios e nascentes saudáveis?

Em toda a trajetória do estudo, pudemos perceber a relevância da pesquisa como estratégia de ensino e conexão entre as áreas de conhecimento; conforme pontua Freire (2002), a pesquisa tem relação direta com o ensino e torna professor e aluno parceiros na construção do conhecimento. A esse respeito, os professores participantes do trabalho, expressam suas opiniões:

[...] a pesquisa é importante e necessária, pois permite que o professor trabalhe com a realidade do aluno, então a aprendizagem não acontece isolada entre quatro paredes, sendo ensinado apenas o que está nos livros didático (P1, entrevista, 09/2009).

Aprendi muito, participando deste trabalho de pesquisa, pois pude trabalhar vários conteúdos, a partir do trabalho no viveiro, e na roça de agrofloresta (P3, entrevista, 10/2009).

[...] Pesquisa para mim é uma metodologia muito importante. Eu acho que a gente constrói conbecimento através de pesquisa. Quando trabalhamos a pesquisa em sala de aula, as crianças se envolvem, se interessam mais nos assuntos estudados. Quando a gente utiliza a pesquisa como uma forma de ensinar a gente faz. uma revolução, em nós mesmos, nas crianças e no nosso grupo (P4, entrevista, 10/2009).

Conforme se observa, os professores revelam a importância da pesquisa como mediação entre a vida e os conhecimentos escolares e para o seu próprio crescimento pessoal e profissional. O fato de estarem em exercício possibilitou, de forma mais significativa, a ação na prática e a reflexão sobre ela, por meio da pesquisa. Rocha (2001, p. 183) corrobora com essa reflexão ao afirmar que:

Os professores em exercício, ao experienciarem outras alternativas de trabalho propostas por novas metodologias e, a aprenderem os conteúdos, iniciam novas formas de ensinar, isto é, continuam aprendendo a como ensinar os seus alunos, bem como continuam aprendendo com as matérias que ensinam. Ensinar e aprender consiste, portanto, em uma ação permanente na vida profissional dos professores [...].

A pesquisa, portanto, é um instrumento valioso para que os professores sejam questionadores, suscitem nos alunos o gosto por tal prática e o prazer em problematizar a realidade vivida. No caso dos professores do campo, oportuniza uma reflexão a respeito da escolha de um ou outro conteúdo, da formação de pessoas com posicionamento crítico e reflexivo e sobre o seu papel na construção de sua própria identidade profissional e da identidade do povo de sua comunidade. Além disso, conforme afirma Paniago (2008, p.57):

[...] é imprescindível que o professor que vive e mora no campo seja peça fundamental na construção de uma proposta que seja desse espaço. A pesquisa no cotidiano se torna peça chave para que o professor do campo possa ser ator na construção da proposta de sua escola. A pesquisa como integrante da prática cotidiana contribuirá para que ele migre da condição de transmissor de conteúdos para a de construtor de conhecimentos. 
Dessa forma, durante a investigação, procuramos suscitar a participação dos professores no processo de pesquisa, por meio do registro das ações e do questionamento reflexivo no grupo. Um dos momentos instigantes do estudo foi o trabalho com o cálculo da área a ser recomposta, cujo formato geométrico é de um triângulo retângulo, em que, em um primeiro momento, recorremos ao cálculo de medidas de área, utilizado na comunidade e, após, foi utilizado o teorema de Pitágoras. Com a obtenção de duas das medidas dos lados do triângulo, foram utilizadas as ideias do grande filósofo grego da Matemática e, por meio do teorema de Pitágoras, os alunos encontraram a outra medida. Além de estudarem a origem do teorema, os alunos foram motivados a estabelecer a relação com os dados levantados acerca das medidas da área, realizaram o desenho dela, considerando os conceitos de escala, razão e proporção, conforme figuras abaixo:

llustração 1 e 2: Planta baixa da área

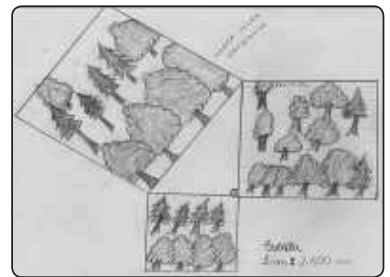

Elaborada pela aluna A3, representa a planta baixa da área a ser recuperada e demais matas ciliares da nascente.

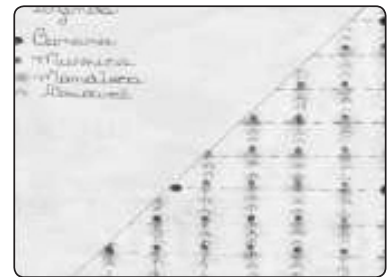

Elaborada pelo aluno A2, representa a forma das espécies a serem plantadas nos sistemas agroflorestais (Safs).

Foto 3: 0 cultivo

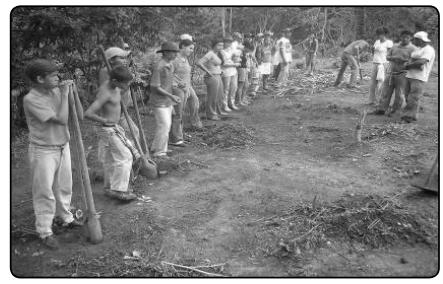

0 cultivo na área por alunos

Fonte: arquivo da pesquisa. e professores.

Encontrando a medida do cateto adjacente ao ângulo reto (lado da mata ciliar da mina) e a hipotenusa (mata ciliar do Sanduzinho, córrego que corta a comunidade), os alunos descobriram a medida do outro cateto. Aplicando o teorema, eles não encontraram um valor exato, fato que os instigou a questionarem: "É incrivel, a matemática do livro é exata e quando a gente pega valores do nossa vida, não dá certo” (Diário de Campo, A1, 06/2008). Essa constatação gerou um desafio: sendo 
a área a ser recuperada um triângulo retângulo, por que o resultado da terceira medida não dava exato, aplicando o teorema de Pitágoras? Nesse sentido, os alunos foram estimulados a recorrerem ao livro didático, para aprofundar o estudo, e a um técnico em agrimensura, para realizar nova medida na área, para verificação das medidas dos lados. E qual não foi a surpresa deles quando descobriram, sob a orientação do referido técnico, que a cerca da área estava torta, por isso, mesmo formando um ângulo de $90^{\circ}$ graus, em certas partes, a medida se alterava.

Ações como essa foram motivadoras e permitiram a constatação de ser fundamental a atuação do professor, como mediador, instigador da curiosidade do aluno, tornando-o um pesquisador. Esse fato revelou a importância de o ensino ser vinculado à vida, ao ambiente natural do aluno, para que a aprendizagem seja significativa. A afirmação contida nos Parâmetros Curriculares para o ensino de Ciências (BRASIL, 1999, p. 27) corrobora com essa reflexão, ao explicitar que:

[...] a mobilização de conhecimentos adquiridos pela vivência e pela cultura relacionados a muitos conteúdos em situações de aprendizagem na escola é um pressuposto básico para a aprendizagem significativa. Assim, o estudo das Ciências Naturais de forma exclusivamente livresca, sem interação direta com os fenômenos naturais ou tecnológicos, deixa enorme lacuna na formação dos estudantes [...].

Após a identificação das espécies nativas, coleta, cultivo no viveiro, preparo da área, foi feito o implante com sistema de agrofloresta, um modo de produção sustentável que exige que os espaços entre as espécies sigam o modo tradicional da agricultura familiar. Para isso, foi preciso investigar o conhecimento popular a respeito dessa forma de plantio e calcular a quantidade de sementes a ser utilizada em cada cova, além do alinhamento em toda a área a ser plantada. A fala do aluno expressa a sua opinião sobre o trabalho: "Desse jeito a gente trabalhou tanta coisa de forma prática com a nossa vida" (Diário de Campo, A1,10/2009); "Eu não imaginava como fica fácil aprender quando o assunto faz parte daqui" (Diário de Campo, A2, 08/2009). A esse respeito fala também outro aluno: "Como é curioso e interessante quando aprendemos por meio de coisas da vida da gente" (Diário de Campo, A3, 10/2009).

No sistema de agrofloresta é preciso fazer a muvuca de sementes, que consiste em misturar todas as que serão plantadas no local, sendo necessário observar a quantidade de sementes de acordo com a espécie, covas e o tempo de crescimento, para que, em cada período, o extrato de uma não sufoque a outra, o que envolve conhecimento sobre o cultivo das espécies exóticas e nativas, lógica matemática e atitude de pesquisa. Assim, nós, investigadoras, incitamos os professores e alunos a questionarem, a problematizarem a sua realidade e a fazerem elaboração própria, tendo a concepção de que, conforme aponta Demo (1998, p.44):

Pesquisar não é somente produzir conhecimentos, é, sobretudo aprender em sentido criativo. É possível aprender escutando aulas, tomando nota, mas aprende-se de verdade quando se parte para a elaboração própria, motivando o surgimento do pesquisador que aprende construindo. 
Dos quatro professores participantes da investigação, três apresentaram trabalhos em eventos científicos. Pode-se citar, ainda, a participação de alunos, como pesquisadores na Mostra Nacional de Ciências e Tecnologia e prêmios ${ }^{5}$ obtidos nos anos de 2008 e 2009.

\section{CONSIDERACְÕES FINAIS}

Por meio do uso da pesquisa como ferramenta pedagógica, caminhamos no sentido de romper com o trabalho desvinculado do ambiente natural do aluno, de seus saberes e cultura. O trabalho revelou a importância da pesquisa como ferramenta de ensino e como veículo de conexão entre os saberes escolares, a história sociocultural do aluno, suas formas concretas de representação social, enfim, a sua forma de viver no campo. Durante o trabalho, as situações-problemas na lida com as sementes, com o plantio e com a terra foram indicadoras do que se poderia trabalhar em Ciências Naturais e em Matemática, revelando a importância do ensino e da aprendizagem não ocorrerem apenas entre quatro paredes, mas de utilizar outros espaços, como a roça, a floresta, os quintais, os rios, a serra. O laboratório vivo do campo oportuniza trabalhar as proposições previstas nas orientações dos documentos oficiais, além de instigar o aluno a problematizar e a fazer intervenção em sua realidade vivida e de contribuir para a construção de uma sociedade sustentável, para a relação com o trabalho e os saberes do homem do campo.

A nossa trajetória de investigação oportunizou-nos vivenciar resultados promissores junto aos alunos, uma vez que eles manifestaram a possibilidade de associarem as aprendizagens significativas no/do espaço e vida do campo aos conhecimentos teóricos. Além disso, este trabalho apontou a importância da formação do professor para a pesquisa como possibilidade significativa para a problematização, intervenção, ressignificação das práticas de ensino, e a necessidade de condições adequadas de trabalho para que a prática de pesquisa seja exercida no cotidiano escolar.

\section{NOTAS}

1 Instituto Socioambiental (ISA) é uma organização não governamental (ONG) que atua na bacia do Xingu e incentiva o desenvolvimento de ações vinculadas às questões ambientais. Para fortalecer nossas ações, buscamos parcerias junto ao ISA e a Prefeitura Municipal de Água Boa.

${ }^{2}$ As Diretrizes Operacionais da Educação do Campo, instituída pela resolução CNE/CEB No. 01 de 03 de abril de 2002, trata da identidade e de especificidades da escola do campo.

\footnotetext{
3 "A técnica denominada agrofloresta (SAF) é [...] a utilização sustentável dos recursos naturais aliada a uma menor dependência de insumos externos que caracterizam este sistema de produção, resultam em maior segurança alimentar e economia, tanto para os agricultores, como para os consumidores". ARMANDO S.M.; BUENO, Y.M. e CAVALCANTE, C.H. Circular Técnica da Embrapa, nº 16.
} 
${ }^{4}$ Em 2009, dois alunos apresentaram a pesquisa intitulada "O pequi: carne do cerrado para o pequeno produtor rural", com o objetivo de refletir sobre a produção sustentável do Pequi na região, sendo vencedores na Mostra de Ciências e Tecnologia Nacional.

${ }^{5}$ Em 2008, os alunos foram vencedores com a pesquisa intitulada "Agrofloresta e matemática: qual a relação?”. Em 2009, com a pesquisa sobre o Pequi.

\section{REFERÊNCIAS}

ANDRÉ, M. (org). O papel da pesquisa na formaşão e na prática dos professores. Campinas: Papirus, 2006.

ARMANDO, S. M.; BUENO, Y. M.; CAVALCANTE, C. H. Agrofloresta para agricultura familiar. Circular técnica da Embrapa, Brasília, n. 16, dezembro, 2003.

ARROYO, Miguel. G. A Educação Básica e o Movimento Social do Campo. In: ARROYO, M.G, CALDART, R.S., MOLINA, M.C (orgs.) Por uma Educaşão do Campo. Petrópolis: Vozes, 2004.

BOGDAN, R e BIKLEN, S. Investigaşão qualitativa em educaşão: uma introdução à teoria e aos métodos. Portugal: Porto Editora, 1994.

BRASIL. Secretaria de Educação Fundamental. Parâmetros Curriculares Nacionais: Ciências Naturais / Secretaria de Educação Fundamental. Brasília: MEC / SEF, 1999.

BRASIL, Ministério da Educação. Proposta de Diretrizes para a Formação Inicial de Professores da Educação Básica em Cursos de Nivel Superior. Brasília: MEC, 2000.

CHALMERS, A.F. A Fabricação da Ciência, São Paulo: Editora da Unesp, 1999.

D`AMBROSIO, U. Educação Matemática: da teoria à prática. Campinas: Papirus, 1999.

DEMO, Pedro. Educar pela pesquisa. 3. ed. Campinas. São Paulo. Autores Associados, 1998.

ELLIOT, J. La investigación-acción em educación. Madrid: Vozes, 2000

FRANCO, Maria Amélia Santoro. Pedagogia da Pesquisa-ação. Educação e Pesquisa, São Paulo, v.31, n.3, p.483-502,2005.

FREIRE, Paulo. Pedagogia do Oprimido. 42. ed. São Paulo: Paz e terra, 2005 . Pedagogia da autonomia: saberes necessários à prática educativa. 21. ed. São Paulo: Paz e terra, 2002.

- Pedagogia da esperança: um reencontro com a pedagogia do oprimido. 13 ed. São Paulo, Paz e terra: 2006.

FIORENTINI, D. ; LORENZATO, S. Investigação em Educação Matemática: Percursos teóricos e metodológicos. 2.ed. Campinas: Autores Associados, 2007.

FOUREZ, Gerard. A construção das ciências: introdução à filosofia e à ética das ciências. São Paulo: Editora da Universidade Estadual Paulista, 1995.

KINCHELOE, J. L. Pesquisa-ação, reforma educacional e pensamento do professor. In: A formação do professor como compromisso politico: mapeando o Pós-Moderno. Porto Alegre: Artes Médicas, 1993. p. 179 -197.

LUDKE, Menga. O professor e a pesquisa. Campinas, São Paulo: Papirus, 2001.

LUDKE, M. (coord.); OLIVEIRA, A.T.C. [et al.]. O que conta como pesquisa? São Paulo: Cortez, 2009.

MOLINA, Mônica Castagna (org.). Educação do Campo e Pesquisa. Brasília: Ministério do Desenvolvimento Agrário, 2006. Disponível em: < www. nead.org.br>. Acesso em: 20/12/2007.

PANIAGO, R. Professores do Campo e a pesquisa no cotidiano escolar em Mato Grosso. 2008. 134f. Dissertação (mestrado em Educação) - Instituto de Educação, Universidade Federal de Mato Grosso, Cuiabá, MT, 2008.

PANIAGO, R; ROCHA, S, A. Etnomatemática e Educação do Campo: caminhos para a aprendizagem significativa da pesquisa na formação profissional. In: GHEDIN, E (org.). Educação do Campo: Epistemologia e práticas. São Paulo: Cortez, 2012, p 395-410.

PEREIRA, J. E; ZEINCHNER, K. M. A pesquisa na formação e no trabalho docente. Belo Horizonte: Autêntica, 2002. 
ROCHA, Simone de Albuquerque. Os professores leigos e o Proformação: uma alternativa possível a partir do projeto piloto de Mato Grosso. Orientador: Cleide Nébias. 2001. 331 f. Tese (Doutorado Universidade Estadual Paulista, Marília, SP, 2001.

SANTOS, W. L. P. Educação científica na perspectiva de letramento como prática social: funções, princípios e desafios. Revista Brasileira de Educação, v. 12, n. 36, p. 474-492, set./dez. 2007.

SCHÖN, Donald. Formar professores como profissionais reflexivos. In: Nóvoa, A. (org.) Os professores e a sua formação. Lisboa: D. Quixote, 1997.

STENHOUSE. Investigación y dessarrollo del curriculum. Madri: Morata, 1987.

TRIVELATO, S. L. F. O Ensino de Ciências e as Preocupações com as Relações CTS. Revista Educação em Foco, Juiz de Fora, v. 5, n. 1, p. 43-54, mar-set/2000, 2000.

Data do Recebimento: 19/09/2013

Data da Aprovação: 23/01/2014

Data da Versão Final: $31 / 01 / 2014$ 